\title{
A Life Cycle-Based Scenario Analysis Framework for Municipal Solid Waste Management
}

\author{
Ioan-Robert Istrate, José-Luis Gálvez-Martos, and Javier Dufour
}

\begin{abstract}
A framework for the systematic analysis of the material flows and the life cycle environmental performance of municipal solid waste (MSW) management scenarios is described in this article. This framework is capable of predicting the response of waste treatment processes to the changes in waste streams composition that inevitably arise in MSW management systems. The fundamental idea is that the inputs (raw materials and energy) and outputs (final products, emissions, etc.) into/ from treatment processes are previously allocated to the specific waste materials contained in the input waste stream. Aggregated indicators like life cycle environmental impacts can then be allocated to waste materials, allowing systematic scenario analyses. The framework is generic and flexible, and can easily be adapted to other types of assessments, such as economic analysis and optimization.
\end{abstract}

\section{Introduction}

Municipal solid waste (MSW) is generally defined as that generated in households and from commercial, institutional, and street cleaning activities with similar composition to the household waste. MSW contains a wide variety of potentially valuable materials (e.g., food waste, paper, cardboard, plastic, and metals) but whose increased generation and inappropriate management cause negative environmental and human health consequences as well as the loss of resources [1]. Decisionmakers are under increasing pressure to adopt MSW management strategies aiming to maximize resource and energy recovery and minimize environmental and human health risks and usually under constrained budget. In Europe, the implementation of

\author{
I.-R. Istrate $(\bowtie) \cdot J$. Dufour \\ IMDEA Energy, Systems Analysis Unit, Móstoles, Spain \\ Rey Juan Carlos University, Chemical and Environmental Engineering Group, \\ Móstoles, Spain \\ e-mail: robert.istrate@imdea.org \\ J.-L. Gálvez-Martos \\ IMDEA Energy, Systems Analysis Unit, Móstoles, Spain
}


waste strategies to meet MSW targets is mandatory for the Member States. Reuse and recycling of MSW shall reach 65\% by 2035 (Directive 2018/851/EC), while the Circular Economy Package refers to a maximum of $10 \%$ landfilling by 2035 . However, only $30 \%$ of the MSW generated in 2017 in Europe was recycled while the average landfill rate was $23 \%$, even though half of the Member States landfilled more than $50 \%$ of their MSW [2].

Handling the complexity of the MSW management system, which encompasses a large number of interconnected processes, remains the main challenge to the development of sustainable MSW management strategies. The waste streams derived from MSW collection and the intermediate waste streams present a heterogeneous composition of a wide variety of waste materials with different physicochemical and biological properties (Fig. 1). The resource and energy recovery rates and the technical, economic, and environmental performance of treatment processes depend to a large extent on the composition and properties of the input waste stream [3]. For example, the global warming impact of landfilling the residual waste stream depends on its content on biodegradable waste materials (food waste, paper, etc.), whereas the global warming impact of its incineration depends on its content on fossil-based waste materials (plastic).

Systems analysis techniques are required to tackle the complexity of the MSW management system and support the design of sustainable waste strategies [4]. Life cycle assessment (LCA) has emerged as the most popular, and there are a number of waste LCA tools available. The ability of linking the life cycle inventory (LCI) of treatment processes (i.e., emissions and resource consumption/recovery) to the composition and properties of the input waste stream was recognized as the key feature of a waste-specific LCA tool [5]. However, most of these tools have been developed with black-box models of treatment processes where inputs and outputs are only linked by unrealistic ratios to total mass of input waste. Recently, increased attention is being devoted to the development of modeling frameworks that allow linking input waste composition, treatment process operation, and outputs through a more appropriate approach to physicochemical and biological mechanistic models [6]. This is achieved by adopting a material flow analysis (MFA) perspective for the modeling of the LCIs of treatment processes [7].

MFA is the central methodology of the industrial ecology, and its goal is to provide a comprehensive and systematic inventory of the input-output flows of

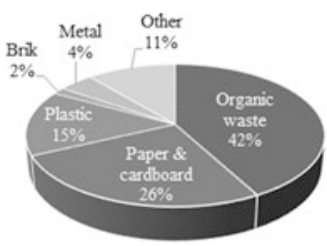

a) Residual waste, households

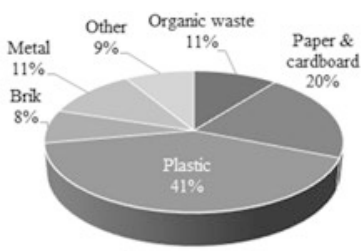

b) Packaging waste, households

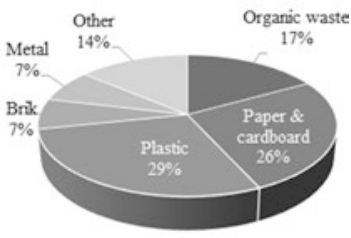

c) Rejected waste, from sorting packaging waste

Fig. 1 Composition of municipal solid waste streams generated in Madrid (2017) 
materials and substances in a system. Mass conservation is the fundamental principle of MFA, i.e., the quantity of input flows has to be equal to the quantity of output flows plus stocks [8]. Thus, MFA provides the appropriate mathematical relationships that describe the mass balance of waste materials and their chemical elements in a specific treatment process as well as the parameters required.

In addition to LCA and MFA, numerous optimization models for MSW management have also been developed. Mathematical programming techniques can provide a powerful framework that considers all the feasible configurations of the MSW management system and identify the best solution according to one or multiple objectives and considering the system's constraints. Typically, optimization models focused on economic objectives, e.g., the minimization of the system's annual cost. Also, the additional consideration of environmental objectives (based on LCA) and resource recovery objectives (based on MFA) has emerged as a recent trend [9]. In order to provide reliable results, optimization models should, as in the case of LCA tools, be able to capture the response of treatment processes to changes in the composition of the input waste stream $[10,11]$. However, the incorporation of this feature leads to complex nonlinear optimization models, and therefore this issue remains little explored so far.

In this article, we describe a framework for the systematic analysis of the material flows and the life cycle environmental performance of MSW management scenarios. The framework is capable of predicting the response of treatment processes to the changes in waste composition that inevitably arise in MSW management systems. Furthermore, the framework is sufficiently generic and flexible to allow incorporating other methods into the assessment, such as economic analysis and optimization. Section 2 describes the framework. Section 3 includes an illustrative example of its application. Section 4 draws the main conclusions and the future work.

\section{Framework Description}

\subsection{Scope and System Boundaries}

Figure 1 illustrates the scope and system boundaries of the framework. Based on the definition of MSW given in the Waste Framework Directive, we considered the waste generated by three sectors: households, commercial activities, and street cleaning. Waste collection at each sector can be defined by combining the five waste streams that could be found in Spanish municipalities: residual, packaging, paper and cardboard, glass, and organic wastes (Fig. 2a). These streams need to be defined in terms of quantity and composition. Waste streams composition is disaggregated into 15 materials: food waste, green waste, mix paper, cardboard, polyethylene terephthalate (PET), high-density polyethylene (HDPE), low-density polyethylene (LDPE), mix plastic, cartons and alike, glass, ferrous metal, nonferrous metal, textile, wood, and other. Furthermore, each waste material is characterized by 83 


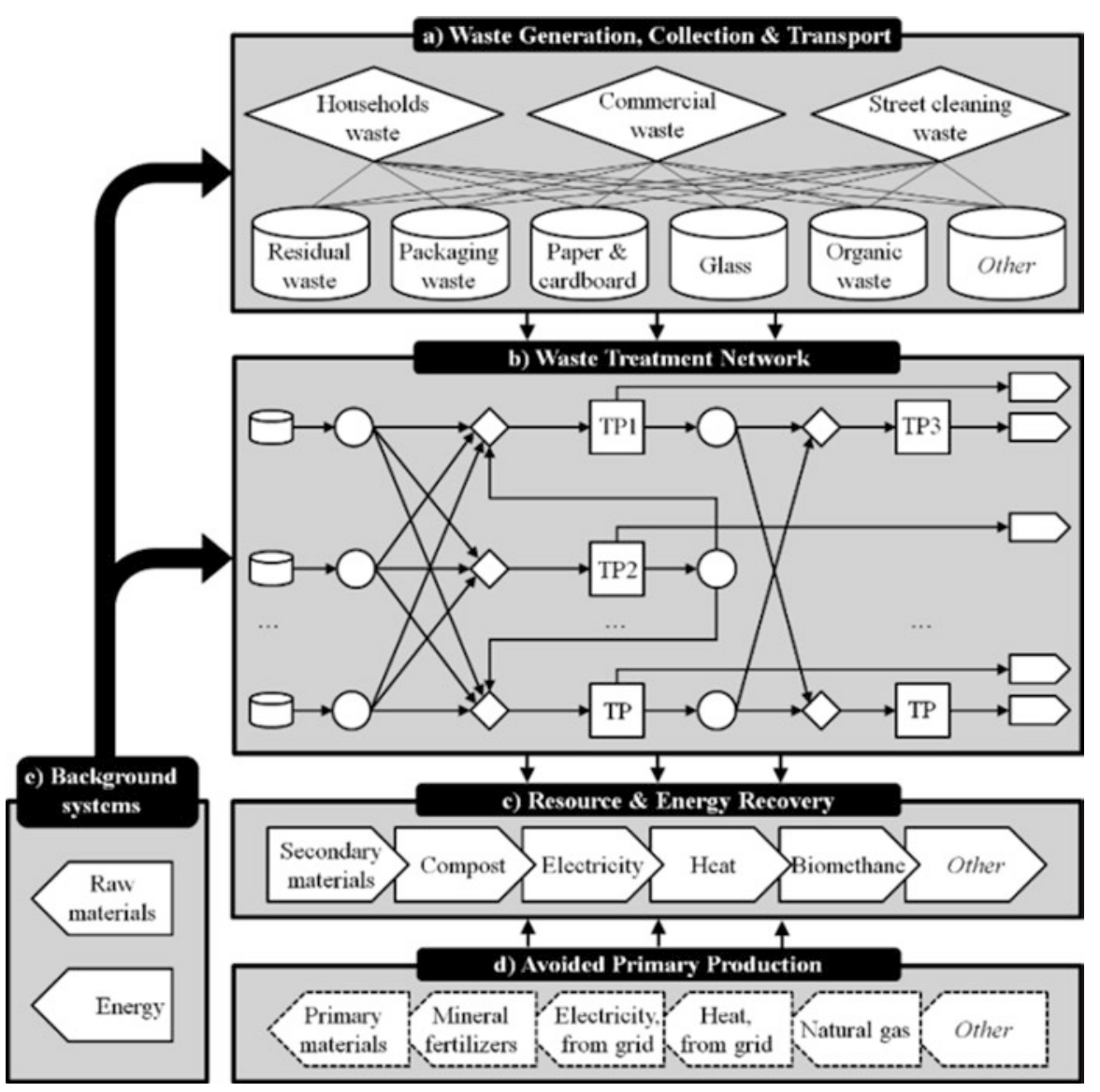

Fig. 2 Scope and system boundaries of the framework

physicochemical and biological properties (e.g., moisture content, lower heating value, biochemical methane potential, chemical elements, etc.).

Collected waste streams are processed in a network of interconnected treatment processes (material recovery facilities, composting, incineration, landfill, etc.) that generate intermediate waste streams (rejected waste, recyclable materials, etc.) and/ or final products (secondary materials, compost, electricity, etc.) (Fig. 2b). While intermediate waste streams need further processing, final products are introduced into the market, thus avoiding primary production (Fig. 2c-d). Additionally, the MSW management system interacts with the background systems that supply raw materials and energy (Fig. 2e). Further details about network structure are provided in Sect. 2.3. 


\subsection{Modular Modeling}

We adopted a modular approach so that the MSW management system was disaggregated into many modules that describe treatment processes [12]. This approach has the advantage that allows combining many technological alternatives. For example, anaerobic digestion (AD) was disaggregated into one module that includes the pre-treatment, reactor, dewatering, and post-treatment unit processes and other four modules for each unit process for the use of the biogas (flare, boiler, combined heat and power, and upgrading). Thus, AD can be combined with any alternative for biogas utilization.

Modules consist of the mathematical equations that describe mass and energy balances as a function of the properties of the input waste stream and the process operation conditions. The inputs (raw materials and energy for operation) and outputs (intermediate waste streams, final products, emissions, etc.) are allocated to the specific waste materials contained in the input waste stream (Fig. 3a), as explained below.

In LCA terminology, modules aim at performing a multi-input allocation of the LCI between the waste materials contained in the input waste stream. According to the ISO 14040/14044 standards recommendations, the allocation of process inputs and outputs should be based on natural causal relationships. We follow the MFA principles to perform the allocation. For example, transfer coefficients are used to model the transfer of input waste materials into the rejected waste stream and the recyclable materials stream in a sorting process. Emissions are allocated based on the physicochemical and biological properties of the waste material. For example, biogenic $\mathrm{CO}_{2}$ emissions from waste materials incineration are linked to their biogenic carbon content. Electricity production is calculated for each waste material based on its lower heating value and the process electricity conversion efficiency. For those environmental exchanges where there is no obvious mathematical relationships, allocation is done on a mass basis.

Once allocated the inputs and outputs, aggregated indicators, such as life cycle environmental impacts (i.e., global warming, human toxicity, etc.) or the economic costs (i.e., operation costs, revenues, etc.), can also be allocated to each specific waste material. Therefore, instead of calculating the global warming impact associated with the incineration of 1 tonne of residual waste with a fixed composition, the module calculates the global warming impact associated with the incineration of 1 tonne of each waste material that may constitute the residual waste. Allocated inputs, outputs, and indicators are stored in non-square matrixes that represent in rows the 15 waste materials considered and in columns the inputs, outputs, and indicators given per tonne of waste material (Fig. 3b).

This approach has the advantage that translates the complex nonlinear mathematical models that describe mass and energy balances in treatment processes (e.g., methane generation in landfill is given by a time-dependent first-order decay equation) into a parametrized model (i.e., linear) that can be used for scenario analysis or optimization (Fig. 3c). 
A Modules allocate inputs and outputs to waste materials

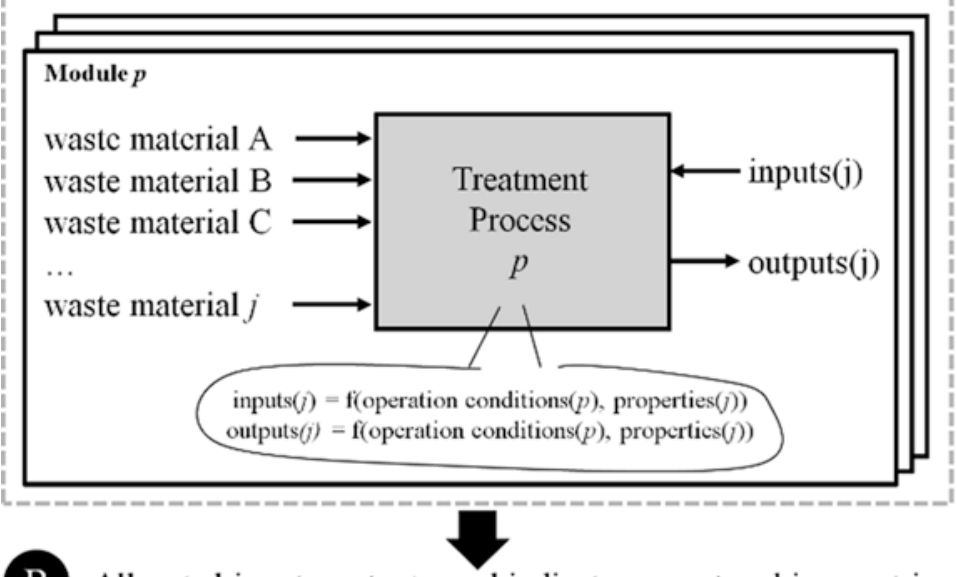

B Allocated inputs, outputs, and indicators are stored in a matrix

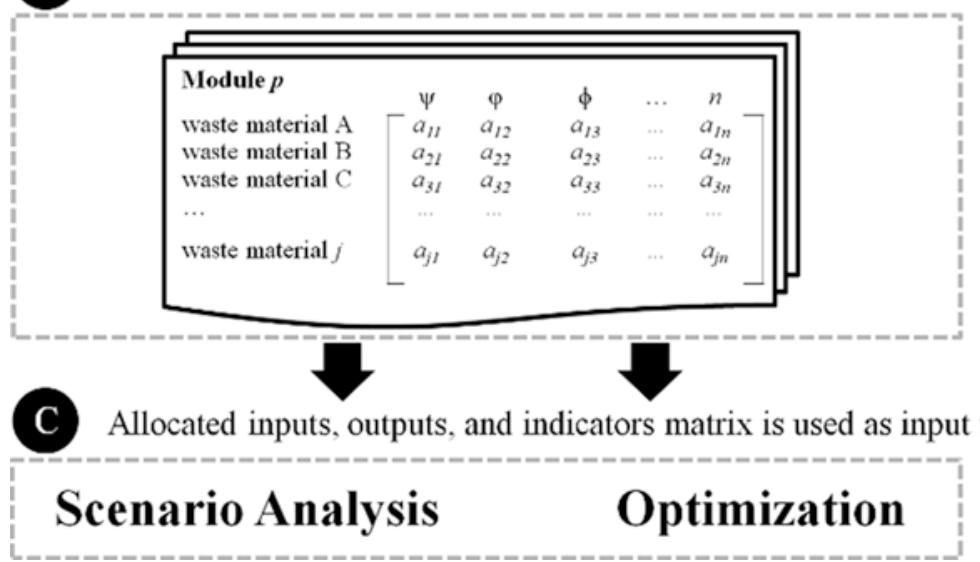

Fig. 3 Modular modeling of treatment processes

\subsection{Scenario Analysis Modeling}

The modules' matrixes of inputs, outputs, and indicators can be used for scenario analysis. All feasible modules combinations for treating household, commercial, and street cleaning waste streams as well as the intermediate waste streams are embedded in a mathematical network (Fig. 2b). The network consists of splitters (circles), mixers (diamonds), modules (boxes), and all their interconnections (arrows).

Splitters are located after each waste stream and assign the waste stream to the linked modules. The partitioning of a waste stream in a splitter between the modules linked is represented by user-defined mass fractions. For example, the mass 
fractions of a splitter for residual waste could be $20 \%$ to incineration and $80 \%$ to landfilling. Note that the waste streams leaving the splitter have the same composition as the input stream because splitters do not involve transformation. Therefore, the mass fraction introduced is applied equally to all the waste materials contained in the waste stream.

Mixers are located after splitters and prior each module. Since modules can receive several waste streams with different composition, the function of mixers is to sum over materials of the same type contained in different waste streams. Mixers do not require input data. Finally, modules performance, for example, the global warming impact of incinerating $20 \%$ of the residual waste, results by multiplying the array of input waste materials by the array of global warming impact contained in the matrix of inputs, outputs, and indicators obtained in Sect. 2.2. The performance of the overall MSW management system is obtained by addition of the performance of all modules. Note that, once the allocated inputs, outputs, and indicators for all modules are obtained, the only requirement to build a scenario is to introduce the mass and composition of the initial waste streams and to fill the mass fractions of all splitters in the network.

\section{Illustrative Scenario Analysis Case Study}

In order to illustrate the applicability of the framework, a streamlined example addressing the global warming consequences of MSW incineration phasing out in Madrid (Spain) is presented. In 2017, about 313,697 t of rejected waste from sorting residual and packaging waste stream at material recovery facilities have been incinerated in Madrid [13]. The new waste strategy of the city aims at phasing out the incineration plant by 2025, which can led to the diversion of huge amounts of waste toward landfilling. In this example, we assess the life cycle global warming impact associated with the management of 1 tonne of rejected waste in Madrid considering different incineration rates. Four scenarios were formulated. S1 considers that 100\% of the rejected waste is incinerated. S2 considers that 75\% is incinerated and 25\% landfilled. S3 considers that 50\% is incinerated and 50\% landfilled. Finally, S4 considers that $100 \%$ is landfilled. The ILCD-recommended characterization factors were used for the assessment [14]. Emissions of biogenic $\mathrm{CO}_{2}$ and the biogenic carbon that remains sequestered in landfill after 100 years were assumed with a characterization factor of 0 .

Table 1 shows the life cycle global warming impact allocated to waste materials as obtained from the incineration and landfilling modules. Incineration was disaggregated into emissions to air (INC [UP_1]), resource consumption (INC [UP_2]), and avoided impacts due to the substitution of electricity from the Spanish mix (INC [UP_3]). Landfilling was disaggregated into dispersive emissions (LAND [UP_1]), resource consumption (LAND [UP_2]), and avoided impacts due to the substitution of electricity from the Spanish mix (LAND [UP_3]). Note that values in Table 1 were computed using technology and operation conditions from Madrid. 
Table 1 Life cycle global warming impact allocated to waste materials for incineration (INC) and landfilling (LAND) for the case study of Madrid $\left(\mathrm{kg} \mathrm{CO}_{2 \text {-eq }} \mathrm{t}^{-1}\right.$ wet waste material)

\begin{tabular}{l|l|l|l|l|l|l}
\hline Waste material & $\begin{array}{l}\text { INC } \\
{[\text { IN_1 }}\end{array}$ & $\begin{array}{l}\text { INC } \\
{[\text { UP_2 }}\end{array}$ & $\begin{array}{l}\text { INC } \\
\text { [UP_3 }]\end{array}$ & $\begin{array}{l}\text { LAND } \\
\text { [UP_1] }\end{array}$ & $\begin{array}{l}\text { LAND } \\
\text { [UP_2] }\end{array}$ & $\begin{array}{l}\text { LAND } \\
\text { [UP_3] }\end{array}$ \\
\hline Food waste & 24 & 12 & -76 & 733 & 0.07 & -110 \\
\hline Green waste & 21 & 6 & -48 & 301 & 0.07 & -43 \\
\hline Mix paper & 11 & 5 & -143 & 1615 & 0.07 & -149 \\
\hline Cardboard & 9 & 4 & -111 & 1045 & 0.07 & -72 \\
\hline PET & 2326 & 6 & -307 & 0 & 0.07 & 0 \\
\hline HDPE & 2499 & 7 & -417 & 0 & 0.07 & 0 \\
\hline LDPE & 1448 & 8 & -218 & 0 & 0.07 & 0 \\
\hline Mix plastic & 2692 & 22 & -417 & 0 & 0.07 & 0 \\
\hline $\begin{array}{l}\text { Cartons and } \\
\text { alike }\end{array}$ & 140 & 6 & -128 & 810 & 0.07 & -56 \\
\hline Glass & 0 & 0 & 0 & 0 & 0.07 & 0 \\
\hline Ferrous metal & 0 & 0 & 0 & 0 & 0.07 & 0 \\
\hline $\begin{array}{l}\text { Nonferrous } \\
\text { metal }\end{array}$ & 0 & 0 & 0 & 0 & 0.07 & 0 \\
\hline Textile & 440 & 46 & -223 & 240 & 0.07 & -22 \\
\hline Wood & 38 & 9 & -206 & 71 & 0.07 & -4 \\
\hline Other & 217 & 8 & -30 & 0 & 0.07 & 0 \\
\hline
\end{tabular}

Table 1 reveals the large differences that exist with respect to the environmental impacts of waste materials. The global warming impact of incinerating plastic is largely higher than other waste materials due to the higher content on fossil carbon. Avoided impacts due to electricity substitution are also higher for plastic due to the higher energy content. Dispersive greenhouse gas emissions from landfill are significantly higher for mix paper, cardboard, and cartons and alike compared to food and green waste. Note that values in Table 1 are expressed per tonne of wet waste material. Although food and green waste have a higher degradation rate compared to paper and cardboard, the former have also higher moisture content. Finally, the global warming impact of resource consumption in landfill (electricity and diesel for landfill operation) is the same for all waste materials. This reflects that energy consumption was allocated on a mass basis because energy is used for waste movement. Consequently, the same impact is obtained per tonne of each waste material.

Figure 4 shows the procedure to build scenarios S1-S4 and how the global warming impact of each scenario is calculated. Quantity (Q) and composition (c) are required as input data in order to define the rejected waste stream. The quantity was assumed 1 wet tonne (functional unit), and the composition is as follows: $13.91 \%$ food waste, $3.52 \%$ green waste, $26.48 \%$ mix paper, $8.46 \%$ cardboard, $2.54 \%$ PET, 1.30\% HDPE, 10\% LDPE, $7.65 \%$ mix plastic, 3.71\% cartons and alike, $3.57 \%$ glass, $1.49 \%$ ferrous metal, $1.11 \%$ nonferrous metal, $10.98 \%$ textile, $5.29 \%$ wood, and $0 \%$ other. The input data into the splitter are the mass fractions of the rejected waste stream to incineration $(\sigma)$ and landfilling $(\omega)$. The allocated global warming impact of incineration INC $(\mathrm{GW})$ and landfilling $\operatorname{LAND}(\mathrm{GW})$ were calculated by 


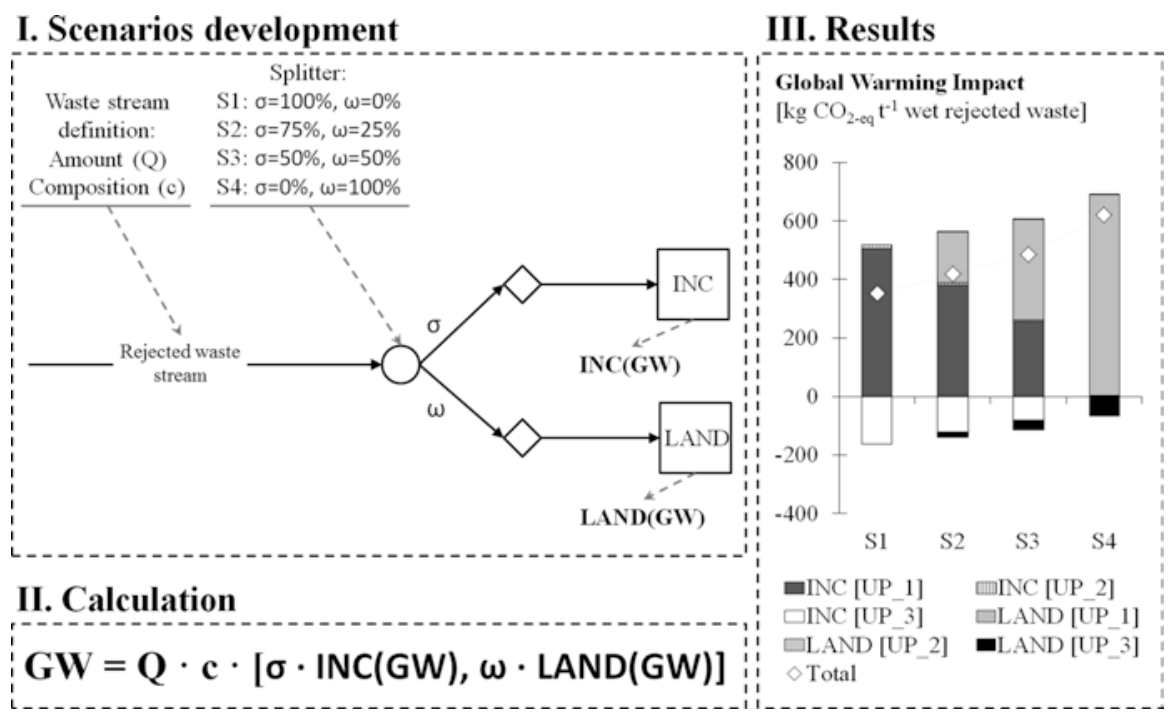

Fig. 4 Scenarios development (I), calculation (I), and global warming impact results (III) for the scenarios addressed

the framework (Table 1). Thus, the global warming impact of each scenario disaggregated by unit processes can be easily obtained.

For this case study, increasing the landfilling of rejected waste at the expense of reducing incineration entails an increase in the global warming impact. The increase is related to the dispersive emissions of methane from landfill. Note that the mix paper and cardboard contained in the rejected waste are significant: $26.48 \%$ and $8.46 \%$, respectively. These waste materials have the highest global warming impact on landfilling. In contrast, their impact on incineration is negligible because biogenic $\mathrm{CO}_{2}$ emissions were considered not to contribute to the global warming impact (Table 1).

Figure 5 shows the global warming impact of S1-S4 as a function of a gradual decrease on mix paper and cardboard content at the expense of an increase on plastic content. The results highlight the key role of waste composition when assessing MSW management systems. In fact, if the rejected waste did not contain mix paper and cardboard but a higher proportion of plastic, landfilling would be a better option than incineration. This is because the global warming impact of plastic in landfill is negligible (Table 1). 
Global Warming Impact

$\left[\mathrm{kg} \mathrm{CO}\right.$ 2-eq $\mathrm{t}^{-1}$ wet rejected waste]

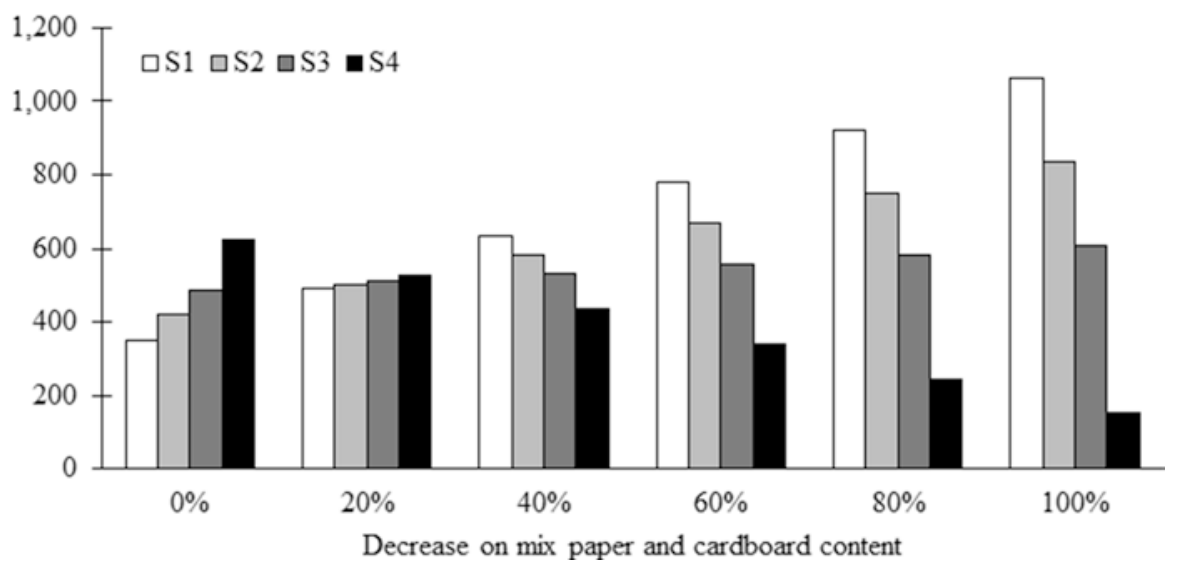

Fig. 5 Global warming impact of S1-S4 as a function of a gradual decrease on mix paper and cardboard content at the expense of an increase on plastic content. (S1, 100\% incineration; S2, $75 \%$ incineration and 25\% landfill; S3, 50\% incineration and 50\% landfill; S4, 100\% landfill)

\section{Conclusions and Future Work}

A framework for the systematic analysis of the material flows and the life cycle environmental performance of municipal solid waste (MSW) management scenarios has been proposed and described in this article. The framework addresses the collection, treatment, and final disposal of household, commercial, and street cleaning waste streams generated in a given region. System boundaries include the network of interconnected treatment processes, the recovery of resource and energy that avoid primary production, as well as other background systems that supply raw materials and energy to the MSW management system.

The framework is based on a modular modeling approach so that the MSW management system was disaggregated into many modules that describe treatment processes (or even stages of treatment processes). All feasible modules combinations are embedded in a network, and therefore any (feasible) MSW management scenario can be addressed. A key feature of the framework is its capability of tackling the assessment of the complex response of treatment processes to the changes in waste streams composition that inevitably arise in MSW management. The fundamental idea is that inputs (raw materials and energy for operation), outputs (final products, emissions, etc.), and aggregated indicators (life cycle environmental impacts, economic costs, etc.) of treatment processes are previously allocated to the specific waste materials contained in the input waste stream.

The framework is generic and flexible to the incorporation of other types of assessments. The allocated inputs, outputs, and indicators can be used as input 
parameters into an optimization model. This represents an enormous advantage since the response of treatment processes to changes in waste composition can be easily evaluated with fixed parameters. There is no need to formulate a mathematical program based on the complex nonlinear models that describe mass and energy balances in waste treatments. The only requirement is to consider as optimization variables the flow of each waste material contained in waste streams. While the modeling approach based on the flow of multi-components has been typically applied in wastewater networks optimization problems, this remains unexplored in the field of MSW management.

Acknowledgments This research has been supported by the Spanish Ministry of Science, Innovation and Universities (RTI2018-097227-B-I00) and a project co-financed by the Connecting Europe Facility of the European Union (Grant Agreement number INEA/CEF/TRAN/ M2016/1359344).

\section{References}

1. Kaza, S., Yao, L., Bhada-Tata, P., \& Van Woerden, F. (2018). What a waste 2.0: A global snapshot of solid waste management to 2050, urban development series. World Bank.

2. Eurostat, Municipal waste statistics (Accessed 10.01.2020).

3. Bisinella, V., Götze, R., Conradsen, K., Damgaard, A., Christensen, T. H., \& Astrup, T. F. (2017). Importance of waste composition for Life Cycle Assessment of waste management solutions. Journal of Cleaner Production, 164, 1180-1191.

4. Pires, A., Martinho, G., \& Bin Chang, N. (2011). Solid waste management in European countries: A review of systems analysis techniques. Journal of Environmental Management, 92(4), 1033-1050.

5. Gentil, E. C., Damgaard, A., Hauschild, M., Finnveden, G., Eriksson, O., Thorneloe, S., Ozge Kaplan, P., Barlaz, M., Muller, O., Matsui, Y., Ii, R., \& Christensen, T. H. (2010). Models for waste life cycle assessment: Review of technical assumptions. Waste Management, 30(12), 2636-2648.

6. Lodato, C., Tonini, D., Damgaard, A., \& Astrup, T. F. (2020). A process-oriented life-cycle assessment (LCA) model for environmental and resource-related technologies (EASETECH). International Journal of Life Cycle Assessment, 25(1), 73-88.

7. Turner, D. A., Williams, I. D., \& Kemp, S. (2016). Combined material flow analysis and life cycle assessment as a support tool for solid waste management decision making. Journal of Cleaner Production, 129, 234-248.

8. Brunner, P. H., \& Rechberger, H. (2004). Practical handbook of material flow analysis. Lewis Publisher.

9. Juul, N., Münster, M., Ravn, H., \& Ljunggren Söderman, M. (2015). Economic and environmental optimization of waste treatment. Waste Management, 38(1), 486-495.

10. Levis, J. W., Barlaz, M. A., DeCarolis, J. F., \& Ranjithan, S. R. (2013). A generalized multistage optimization modeling framework for life cycle assessment-based integrated solid waste management. Environmental Modelling \& Software, 50, 51-65.

11. Roberts, K. P., Turner, D. A., Coello, J., Stringfellow, A. M., Bello, I. A., Powrie, W., \& Watson, G. V. R. (2018). SWIMS: A dynamic life cycle-based optimisation and decision support tool for solid waste management. Journal of Cleaner Production, 196, 547-563. 
12. Haupt, M., Kägi, T., \& Hellweg, S. (2018). Modular life cycle assessment of municipal solid waste management. Waste Management, 79, 1-13.

13. Madrid City Council, Memoria de Actividades de la Dirección General del Parque Tecnológico de Valdemingómez - 2017, 2019.

14. Fazio, S., Castellani, S., Sala, V., Schau, S., Secchi, E., \& Zampori, M. (2018). Supporting information to the characterisation factors of recommended EF Life Cycle Impact Assessment method. European Commission.

Open Access This chapter is licensed under the terms of the Creative Commons Attribution 4.0 International License (http://creativecommons.org/licenses/by/4.0/), which permits use, sharing, adaptation, distribution and reproduction in any medium or format, as long as you give appropriate credit to the original author(s) and the source, provide a link to the Creative Commons license and indicate if changes were made.

The images or other third party material in this chapter are included in the chapter's Creative Commons license, unless indicated otherwise in a credit line to the material. If material is not included in the chapter's Creative Commons license and your intended use is not permitted by statutory regulation or exceeds the permitted use, you will need to obtain permission directly from the copyright holder. 